[4] Sieper, J. et al., Ann Rheum Dis, 2012; 71:700-6.

Acknowledgements: AbbVie funded the study (NCT00085644), contributed to its design, and participated in data collection, analysis and interpretation of the data, and in writing, review, and approval of the publication. Medical writing support was provided by Deepa Venkitaramani, PhD, of AbbVie.

Disclosure of Interest: J. Sieper Grant/research support from: AbbVie, Lilly, Janssen, Merck, Novartis, Pfizer, Roche, Sun Pharma, and UCB, Consultant for: AbbVie, Lilly, Janssen, Merck, Novartis, Pfizer, Roche, Sun Pharma, and UCB, Speakers bureau: AbbVie, Lilly, Janssen, Merck, Novartis, Pfizer, Roche, Sun Pharma, and UCB, A. Deodhar Grant/research support from: AbbVie, Amgen, Eli Lilly, Glaxo-Smith-Kline, Merck-Sharp-Dohme, Novartis, Pfizer, Sun Pharma, and UCB, Consultant for: AbbVie, Amgen, Eli Lilly, Glaxo-Smith-Kline, Merck-Sharp-Dohme, Novartis, Pfizer, Sun Pharma, and UCB, Speakers bureau: AbbVie, Amgen, Eli Lilly, Glaxo-Smith-Kline, Merck-Sharp-Dohme, Novartis, Pfizer, Sun Pharma, and UCB, M. Hojnik Shareholder of: AbbVie, Employee of: AbbVie, Y. Zhang Shareholder of: AbbVie, Employee of: AbbVie, M. Dougados Grant/research support from: AbbVie, Lilly, Merck, Novartis, Pfizer, Sanofi, and UCB, Consultant for: AbbVie, Lilly, Merck, Novartis, Pfizer, Sanofi, and UCB, Speakers bureau: AbbVie, Lilly, Merck, Novartis, Pfizer, Sanofi, and UCB DOI: 10.1136/annrheumdis-2017-eular.1302

\section{THU0380 RESULTS OF A REAL LIFE DOSE-REDUCTION STRATEGY FOR ANTI-TNFALPHA INHIBITORS IN A COHORT OF PATIENTS WITH SPONDYLOARTHRITIS}

M.C. Castro-Villegas ${ }^{1,2}$, P. Font-Ugalde ${ }^{1,2,3}$, M. Romero-Gomez ${ }^{1,2}$, M. Arredondo-López ${ }^{3}$, E.C. López-Medina ${ }^{1}$, R. Ortega-Castro ${ }^{1,2}$,

J. Calvo-Gutierrez ${ }^{1,2,3}$, A. Escudero-Contreras ${ }^{1}$, E. Collantes-Estévez ${ }^{1,2,3}$

${ }^{1}$ Reina Sofía University Hospital; ${ }^{2}$ IMIBIC; ${ }^{3}$ Universidad de Córdoba, Cordoba, Spain

Background: Published reports suggest that patients with Spondyloartrhitis $(\mathrm{SpA})$ in remission under treatment with TNFalpha inhibitors (TNFi) could obtain the same benefit at lower dose of the drug.

Objectives: To evaluate effectiveness of a strategy of dose reduction of TNFi in SpA patients in clinical remission and to explore baseline characteristics predictive of maintenance of the response.

Methods: Retrospective observational study, including patients with SpA meeting ASAS criteria treated with TNFi following a dose optimization protocol (lower doses or longer intervals than aproved), from 2008 to 2015. Criteria for optimization was patients with $B A S D A I<2$ and/or $C$ reactive protein level $(C R P) \leq 5 \mathrm{mg} / \mathrm{L}$ for at least 6 months. Patients who relapsed (BASDAl $>2$ and/or $C R P>5 \mathrm{mg} / \mathrm{L}$ ) returned to standard dose. Clinical/analytical parameters and drug's survival time until relapse were recorded. SPSSv.17 software was used for contrast means. Survival Kaplan-Meyer curves was analysed.

Results: 149 SpA patients treated with TNFi, 32/149 patients (21.5\%) included in optimization protocol. 27 patients $(84.37 \%)$ with increased interval between doses, remaining with reduced dosification. Table 1 shows baseline characteristics of patients on optimization group (mean $\pm S D$ or proportion). 18/32 patients (56.2\%,IC:39.01-73.4) maintained clinical remission with optimized dose at 36.5 months (median). Table 2 shows activity parametres of both relapsed and maintained response patients. There were either baseline differences or at optimization time between patients who maintained remission and not, but relapsed patients showed higher CRP at optimization time, without statistically significant differences. $72.2 \%(13 / 18)$ of patients on sutained remission were naive for TNFi, although no significant difference compared to switcher patients on the median survival (31.9 vs 20.9 months, $P=0.9$ ). No baseline predictor of

Table 1

\begin{tabular}{|c|c|c|}
\hline & \multicolumn{2}{|c|}{ Optimized patients ( $n=32)$} \\
\hline Age (years) & \multicolumn{2}{|c|}{$47.2 \pm 10.6$} \\
\hline Gender (\%) Male/Female & \multicolumn{2}{|c|}{$84.4 / 15.6$} \\
\hline \multirow[t]{2}{*}{ Disease duration (years) } & \multicolumn{2}{|c|}{$12.2 \pm 10.4$} \\
\hline & Baseline & Optimization time \\
\hline BASDAI (0-10) & $4.2 \pm 2,6$ & $2.1 \pm 2.2$ \\
\hline BASFI $(0-10)$ & $4 \pm 2.7$ & $2.8 \pm 2.9$ \\
\hline $\operatorname{ESR}\left(\mathrm{mm} / 1^{\circ} \mathrm{h}\right)$ & $19 \pm 20.1$ & $8.5 \pm 8.5$ \\
\hline $\mathrm{CRP}(\mathrm{mg} / \mathrm{L})$ & $13.1 \pm 18.7$ & $6.4 \pm 9.7$ \\
\hline Number of previous TNFi & \multicolumn{2}{|c|}{$0.3 \pm 0.6$} \\
\hline \multicolumn{3}{|l|}{ Current TNFi (\%) } \\
\hline Infliximab & \multicolumn{2}{|c|}{$31.3 \%$} \\
\hline Adalimumab & \multicolumn{2}{|c|}{$21.9 \%$} \\
\hline Etanercept & \multicolumn{2}{|c|}{$25 \%$} \\
\hline Golimumab & \multicolumn{2}{|c|}{$21.9 \%$} \\
\hline
\end{tabular}

Table 2

\begin{tabular}{|c|c|c|c|c|c|c|}
\hline & \multicolumn{3}{|c|}{ Not-sustained remission $(n=14)$} & \multicolumn{3}{|c|}{ Sustained Remission $(n=18)$} \\
\hline & Basaline & Optimization time & Flare time & Basaline & Optimization time & Last visit \\
\hline & $3.8 \pm 2.4$ & & $2.4 \pm 1$ & & & \\
\hline & & & & & & \\
\hline & & & & & & $8 \pm 6$ \\
\hline $\mathrm{CRP}(\mathrm{mg} / \mathrm{L})$ & $10.9 \pm 12.2$ & $9.7 \pm 12.4$ & $3.4 \pm 5.7^{\star \#}$ & $14.6 \pm 22.5$ & $3.7 \pm 6.1^{*}$ & $2.5 \pm 5^{*}$ \\
\hline
\end{tabular}

Statistical significant differences: ${ }^{*}$ compare to baseline; ${ }^{*}$ compared to optimization time. sustained response at optimized dose were found. CRP $<5 \mathrm{mg} / \mathrm{L}$ at optimization time showed a trend towards longer survival (43.4 vs 13.3 months), without differences statistically significant $(\mathrm{p}=0.09)$.

Conclusions: Optimization of TNFi in SpA is possible and allows up to half of patients to maintain clinical remission, but no baseline factors predictors of sustained response after optimization was found.

Disclosure of Interest: None declared

DOI: 10.1136/annrheumdis-2017-eular.2633

\section{THU0381 CERTOLIZUMAB PEGOL IS EFFECTIVE IN UVEITIS ASSOCIATED TO SPONDYLOARTHRITIS REFRACTORY TO OTHER TUMOUR NECROSIS FACTOR INHIBITORS}

M.V. Hernández ${ }^{1}$, M. Mesquida ${ }^{2}$, V. Llorens ${ }^{2}$, M. Sainz de la Maza ${ }^{2}$, R. Blanco ${ }^{3}$, V. Calvo ${ }^{3}$, O. Maiz ${ }^{4}$, A. Blanco ${ }^{5}$, A. Urruticoechea ${ }^{6}$, J.R.D.D. Jiménez de Aberásturi ${ }^{7}$, P. Ahijado ${ }^{8}$, E. Judez ${ }^{9}$, P. Tejón ${ }^{10}$, S. Peña ${ }^{11}$, A. Adan ${ }^{2}$, R. Sanmartí ${ }^{1} \cdot{ }^{1}$ Rheumatology; ${ }^{2}$ Ophtalmology, Hospital Clínic, Barcelona; ${ }^{3}$ Rheumatology, Hospital Marqués de Valdecilla, Santander; ${ }^{4}$ Rheumatology; ${ }^{5}$ Ophtalmology, Hospital Universitario Donostia, San Sebastián; ${ }^{6}$ Rheumatology, Hospital Can Misses, Ibiza; ${ }^{7}$ Rheumatology, Txagorritxu Hospital, Vitoria; ${ }^{8}$ Rheumatology, Hospital Universitario Infanta Elena, Madrid; ${ }^{9}$ Rheumatology, Complejo Hospitalario Universitario de Albacete, Albacete; ${ }^{10}$ Rheumatology; ${ }^{11}$ Ophtalmology, Hospital Universitario General de Castellón, Castellón, Spain

Background: Uveitis is one of the most common extra-articular manifestations of patients with spondyloarthritis $(\mathrm{SpA})$. In severe cases, uveitis may require the use of biological therapy, primarily tumor necrosis factors inhibitors (TNFi), being the most currently used infliximab and adalimumab. However, another TNFi such as certolizumab pegol (CZP), with indication for SpA patients, could be an effective option in cases of inefficacy or adverse events to other TNFi, as we have previously reported (1).

Objectives: Our objective is to analyze the effectiveness and the safety profile of CZP in patients with refractory SpA-associated-uveitis

Methods: Observational, multicentric, retrospective study. We selected all patients with a diagnosis of SpA (including ankylosing spondylitis (AS), psoriatic arthritis (PsA), non-radiographic axial SpA (nr-axSpA) and SpA associated to inflammatory bowel disease (IBD-SpA)) who had refractory uveitis (confirmed by an Ophthalmologist) as main extra-articular manifestation, and who received CZP for at least 6 months. Variables analyzed: age, sex, diagnosis, type of uveitis, duration since the first uveitis episode and number of eyes affected; previous treatment (NSAID, disease-modifying anti-rheumatic drugs (DMARDs), immunossuppressive or biological therapy); outcome, and time to follow-up.

Results: Twenty-four eyes of 13 patients (10 men); age 49.5 11.7 (range 29-71 years) were included in the study. Diagnosis were: seven AS, four PsA, one nr-axSpA, and one IBD-SpA. Type of uveitis: 9 anterior, 3 panuveitis, and

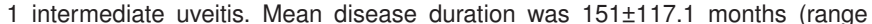
$5-420) .84 .6 \%$ patients had previously received biological therapy $(46.1 \% \geq 2$ biological agents). $61.5 \%$ received CZP in monotherapy and 5 patients received concomitant treatment: 4 methotrexate and 1 azathioprine. In all cases CZP was started due to inefficay to previous treatment except for 2 cases whose primary reason was the occurrence of adverse events (one injection site reaction and one development of relapsing polychondritis). After a follow-up of $13.1 \pm 6.6$ months (range 6-27), 9 patients are still on CZP treatment. Ten eyes showed improvement of visual acuity $(41.7 \%), 10$ remained stable and 2 worsened. During the follow-up no serious adverse events were reported. Four cases withdrew CZP treatment: 2 due to worsening of articular symptoms but with no uveitis activity; 1 due to macular edema and 1 due to uveitis activity. One patient switch to infliximab, one to golimumab, and 2 required switch to tocilizumab. In all 13 patients except 2, CZP achieved a good control of SpA activity.

Conclusions: CZP demonstrated effectiveness in patients with uveitis-associated to SpA refractory to previous TNFi treatment.

References:

[1] Llorenç V et al. Ocul Immunol Inflamm. 2016; 24: 167-72.

Disclosure of Interest: None declared

DOI: 10.1136/annrheumdis-2017-eular.4425

\section{THU0382 CHANGE IN SACROILIAC JOINT STRUCTURAL RADIOGRAPHIC DAMAGE AFTER TWO YEARS OF ETANERCEPT THERAPY IN COMPARISON TO A CONTEMPORARY CONTROL COHORT IN NON-RADIOGRAPHIC AXIAL SPONDYLOARTHRITIS}

M. Dougados ${ }^{1}$, W.P. Maksymowych ${ }^{2}$, R. Landewe ${ }^{3}$, A. Molto ${ }^{1}$,

P. Claudepierre ${ }^{4}$, M. de Hooge ${ }^{5}$, R.G. Lambert ${ }^{2}$, R. Bonin ${ }^{6}$, J.F. Bukowski ${ }^{6}$ H. Jones ${ }^{6}$, I. Logeart ${ }^{7}$, R. Pedersen ${ }^{6}$, A. Szumski ${ }^{8}$, B. Vlahos ${ }^{6}$, D. van der Heijde ${ }^{5} .{ }^{1}$ Paris Descartes University, Hôpital Cochin, Paris, France; ${ }^{2}$ University of Alberta, Edmonton, Canada; ${ }^{3}$ Amsterdam Rheumatology \& Immunology Center, Amsterdam, Netherlands; ${ }^{4}$ Universite Paris Est Creteil, Creteil, France; ${ }^{5}$ Leiden University Medical Center, Leiden, Netherlands; ${ }^{6}$ Pfizer, Collegeville, United States; ${ }^{7}$ Pfizer, Paris, France, ${ }^{8}$ InVentiv Health, Princeton, United States

Background: Despite the well-known symptomatic and anti-inflammatory effect 
of TNF inhibitors in axial SpA (axSpA), demonstrating a structural effect is challenging.

Objectives: To compare 2 yrs of radiographic sacroiliac joint (SIJ) changes in pts receiving etanercept (ETN) in a clinical trial to similar pts not receiving biologics in a cohort study.

Methods: Pts had recent onset non-radiographic (nr)-axSpA fulfilling ASAS criteria. Study group: pts receiving ETN $50 \mathrm{mg}$ once weekly for 2 yrs in EMBARK (NCT01258738). Control group: pts in an ongoing longitudinal cohort study not receiving biologics for 2 yrs (DESIR, NCT01648907). Outcome measure: change in x-ray SIJ score per mNY criteria (0-4 per SIJ). X-rays were read by 3 experienced readers unaware of image chronology and pt group. Primary endpoint: change (mean of 3 readers) in total SIJ score $(-8$ to +8$)$. Binary endpoints: (1) shift from baseline (BL) $\mathrm{mNY}+$ to wk-104 mNY- and vice versa; (2) change in SIJ score $\geq 1$ (left or right SIJ); (3) change in SIJ score $\geq 1$ in $\geq 1$ SIJ, with change from 0 to 1 and from 1 to 0 considered no change. Treatment effect was analyzed without and with adjustment for the baseline $(\mathrm{BL})$ covariates of sex, symptom duration, smoking status, HLA-B27 status, ASDAS-CRP, SPARCC MRI SIJ score, and SIJ radiography score.

Results: At BL, the control (DESIR, N=197) and ETN (EMBARK, N=164) cohorts differed significantly in all covariates listed above. The difference in change in total SIJ score for control vs ETN, adjusted for covariates, was small but significant: least-squares mean $(95 \% \mathrm{Cl})$ : $0.08(-0.03,0.20)$ vs $-0.14(-0.26,-0.01) ; p=0.008$. The table presents $\mathrm{x}$-ray changes. When adjusted for covariates, the mean difference between control and ETN was significant for 2 of the 3 binary endpoints (table).

Conclusions: This analysis confirms the slow rate of radiographic SIJ progression over 2 yrs in nr-axSpA. The observed data suggest a lower rate of progression with ETN than without a TNF inhibitor.

Disclosure of Interest: M. Dougados Grant/research support from: Pfizer, Abbvie, UCB, Merck, Lilly, Sanofi, Consultant for: Pfizer, Abbvie, UCB, Merck, Lilly, Sanofi, W. P. Maksymowych Grant/research support from: AbbVie, Pfizer, Sanofi, Consultant for: AbbVie, Amgen, Eli Lilly, Janssen Pharmaceutica, L.P, Novartis, Pfizer, Sanofi, UCB, R. Landewe Grant/research support from: Abbott, Amgen, Centocor, Novartis, Pfizer, Roche, Schering-Plough, UCB, Wyeth, Consultant for: Abbott/Abbvie, Ablynx, Amgen, Astra-Zeneca, BMS, Celgene, Janssen (formerly Centocor), Galapagos, GSK, Novartis, Novo-Nordisk, Merck, Pfizer, Roche, Schering-plough, TiGenix, UCB, Wyeth, Employee of: Is a director of Rheumatology Consultancy BV, A. Molto Grant/research support from: Pfizer, UCB, Consultant for: Abbvie, BMS, MSD France- Merck, Pfizer, UCB, P. Claudepierre Grant/research support from: Pfizer, Roche-Chugai, MSD, Consultant for: Abbvie, BMS, Celgene, Janssen, Novartis, Merck, Pfizer, Roche, UCB, M. de Hooge: None declared, R. G. Lambert Consultant for: Bioclinica, R. Bonin Shareholder of: Pfizer, Employee of: Pfizer, J. Bukowski Shareholder of: Pfizer, Employee of: Pfizer, $\mathrm{H}$. Jones Shareholder of: Pfizer, Employee of: Pfizer, I. Logeart Shareholder of: Pfizer, Employee of: Pfizer, R. Pedersen Shareholder of: Pfizer, Employee of: Pfizer, A. Szumski Employee of: InVentiv Health, B. Vlahos Shareholder of: Pfizer, Employee of: Pfizer, D. van der Heijde Consultant for: AbbVie, Amgen, Astellas, AstraZeneca, BMS, Boeringer Ingelheim, Celgene, Daiichi, Eli-Lilly, Galapagos, Gilead, Janssen, Merck, Novartis, Pfizer, Regeneron, Roche, Sanofi, UCB, Employee of: Director of Imaging Rheumatology bv. DOI: 10.1136/annrheumdis-2017-eular.1860

\section{THU0383 INCIDENCE OF UVEITIS IN NON-STEROIDAL ANTI-INFLAMMATORY DRUGS VERSUS TUMOR NECROSIS FACTOR INHIBITORS USERS AMONG PATIENTS WITH ANKYLOSING SPONDYLITIS: A RETROSPECTIVE COHORT STUDY}

M.J. Kim, E.E. Lee, E.Y. Lee, Y.W. Song, E.B. Lee. Division of Rheumatology, Department of Internal Medicine, Seoul National University Hospital, Seoul, Korea, Republic Of

Background: Uveitis associated with ankylosing spondylitis (AS) often recurs and may lead to ocular complications. It remains to be known whether non-steroidal anti-inflammatory drugs (NSAIDs) or TNF inhibitors (TNFi) is more effective in reducing the recurrence of uveitis in patients with AS.

Objectives: To evaluate the effect of NSAIDs and TNFi on preventing recurrence of uveitis in patients with AS.

Methods: This retrospective cohort study included 1061 patients diagnosed with AS at Seoul National University Hospital between January 2004 and December 2015. Patients' clinical factors and laboratory findings were collected from the patients' electric medical records. Patients were divided into those who were treated with NSAIDs $(n=623)$ or TNFi $(n=438)$ which included etanercept, adalimumab, infliximab and golimumab. The incidence rates of new-onset uveitis during each treatment was compared using Cox proportional hazard model after adjusting age, sex, disease duration, history of uveitis, smoking status, ESR, CRP, and HLA-B27. Propensity-score matched comparison was also performed as sensitivity analysis ( $n=168$ in the TNFi group and $n=168$ in the NSAID group). Results: Among the 1061 patients, those in the TNFi group had longer disease duration (11.75 \pm 7.14 vs $6.22 \pm 4.42$ years), higher ESR, CRP level $(40.97 \pm 33.87$ vs $23.32 \pm 22.09 \mathrm{~mm} / \mathrm{h}, 2.69 \pm 3.41$ vs $1.12 \pm 1.93 \mathrm{mg} / \mathrm{L}$, respectively) and higher proportion of patients who had previous history of uveitis before the treatment (22.4 vs $15.4 \%)$. The incidence rates of uveitis were $3.60(95 \% \mathrm{Cl} 2.97$ to 4.42$)$ per 100 person-year in the NSAID group and 6.03 (95\% Cl 5.15 to 7.04$)$ per 100 person-year in the TNFi group. The adjusted hazard ratio for the new-onset uveitis during the treatment in the TNFi group versus the NSAID group was 1.28 (95\% $\mathrm{Cl} 0.80$ to 2.06) ( $p=0.304)$. When compared with NSAID group, etanercept group showed higher incidence of uveitis than the other TNFi: etanercept (HR 1.96 [1.41 to 2.74]), adalimumab (HR 0.65 [0.40 to 1.05]), infliximab (HR 0.50 [0.22 to 1.14]) and golimumab (HR 0.79 [0.25 to 2.50]). The propensity score-matched population was also consistent with the crude comparison between NSAID group and TNFi group (HR 1.29 [0.73 to 2.28]) $(p=0.388)$.

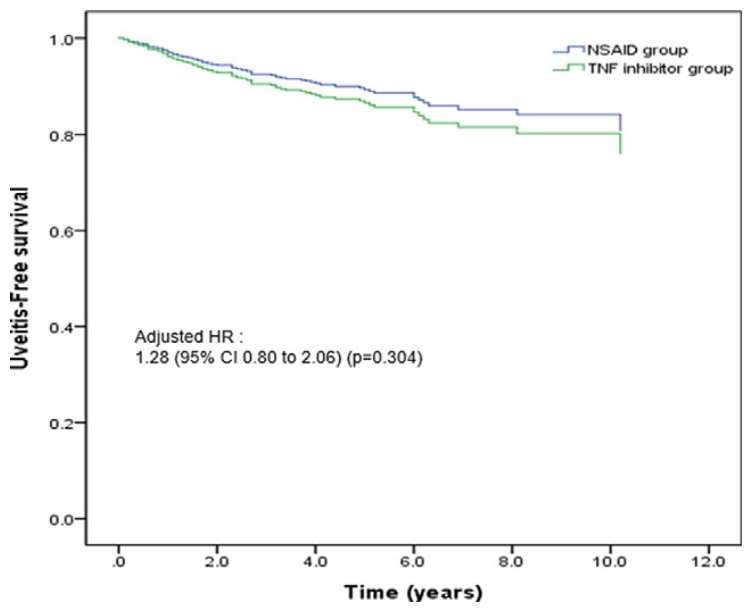

Conclusions: The effect of TNFi on reducing the incidence of uveitis is comparable to NSAIDs in patients with AS. Uveitis occurred more commonly with treatment with etanercept compared with the other treatments.

Disclosure of Interest: None declared

DOI: 10.1136/annrheumdis-2017-eular.3424

\section{THU0384 THE EFFECT AND SAFETY OF YISAIPU (YISAIPU) IN THE TREATMENT OF PATIENTS WITH NONRADIOGRAPHIC AXIAL SPONDYLOARTHRITIS IN CHINA}

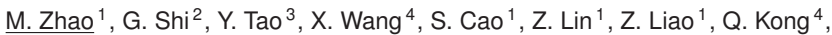
J. Gu ${ }^{1} .{ }^{1}$ Rheumatology department, The Third Affiliated Hospital of Sun Yat-sen University, Guangzhou; ${ }^{2}$ Rheumatology department, The First Affiliated Hospital of Xiamen University, Xiamen; ${ }^{3}$ Rheumatology department, The Second Affiliated Hospital of Guangzhou Medical University; ${ }^{4}$ Radiology department, The Third Affiliated Hospital of Sun Yat-sen University, Guangzhou, China

Background: Axial spondyloarthritis (axSpA) is a chronic inflammatory disease, which includes AS and nr-axSpA. Anti-TNF- $\alpha$ agents, such as Yisaipu (Yisaipu) are frequently used in nr-axSpA patients in China, but the related data is limited. Objectives: The aim of this research is to assess the efficacy and safety of Yisaipu in the treatment of patients with nr-axSpA in China.

Methods: The inclusion of study population consisted of 150 patients who met the ASAS criteria for axial SpA but not the modified New York radiographic criteria for AS, had a score of $\geq 4$ on the BASDAI or a score of $\geq 2.1$ on the ASDAS-CRP and had been treated unsuccessfully with $\geq 1$ NSAIDs for 4 -week. Patients were assigned to receive Yisaipu (made in China) $50 \mathrm{mg} /$ week and continued background NSAID treatment for 24 weeks (open-label study). At week 24 , the

Abstract THU0382 - Table 1. Observed Radiographic Changes from BL to Week 104

\begin{tabular}{|c|c|c|c|c|c|}
\hline Endpoint & Cohort & $\begin{array}{l}\text { Improved } \\
\mathrm{n} / \mathrm{N}(\%)\end{array}$ & $\begin{array}{l}\text { Worsened } \\
\mathrm{n} / \mathrm{N}(\%)\end{array}$ & $\begin{array}{l}\text { Mean Difference }{ }^{\star} \\
\quad(95 \% \mathrm{CI})^{\dagger}\end{array}$ & $\begin{array}{c}\text { Mean differences (Control - ETN) } \\
(95 \% \mathrm{Cl})\end{array}$ \\
\hline mNY criteria & $\begin{array}{l}\text { Control } \\
\text { ETN }\end{array}$ & $\begin{array}{l}3 / 193(1.6) \\
4 / 161(2.5)\end{array}$ & $\begin{array}{l}6 / 193(3.1) \\
1 / 161(0.6)\end{array}$ & $\begin{array}{c}1.6 \%(-1.5,4.6) \\
-1.9 \%(-4.6,0.9)\end{array}$ & $\begin{array}{l}3.4 \%(-0.7,7.5)^{\dagger} \\
4.7 \%(-0.5,9.9)^{\ddagger}\end{array}$ \\
\hline$\Delta \geq 1$ grade in $\geq 1 \mathrm{SIJ}$ & $\begin{array}{l}\text { Control } \\
\text { ETN }\end{array}$ & $\begin{array}{l}21 / 193(10.9) \\
19 / 161(11.8)\end{array}$ & $\begin{array}{c}36 / 193(18.7) \\
16 / 161(9.9)\end{array}$ & $\begin{array}{l}7.8 \%(0.1,15.4) \\
-1.9 \%(-9.1,5.4)\end{array}$ & $\begin{array}{c}9.6 \%(-0.9,20.2)^{\dagger} \\
18.2 \%(5.6,30.9)^{\ddagger \S}\end{array}$ \\
\hline$\Delta \geq 1$ grade in $\geq 1 \mathrm{SIJ} ; \Delta$ from 0 to 1 and 1 to 0 considered no $\Delta$ & $\begin{array}{l}\text { Control } \\
\text { ETN }\end{array}$ & $\begin{array}{l}16 / 193(8.3) \\
15 / 161(9.3)\end{array}$ & $\begin{array}{c}29 / 193(15.0) \\
14 / 161(8.7)\end{array}$ & $\begin{array}{l}6.7 \%(-0.1,13.5) \\
-0.6 \%(-7.2,6.0)\end{array}$ & $\begin{array}{c}7.4 \%(-2.1,16.8)^{\dagger} \\
16.4 \%(5.1,27.8)^{\ddagger \S}\end{array}$ \\
\hline
\end{tabular}

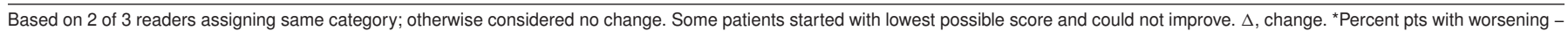
percent pts with improvement. ${ }^{\dagger}$ One-way ANOVA. ${ }^{\ddagger}$ Adjusted for covariates listed in Methods. ${ }^{\S} P=0.005$. 